INTERNATIONAL JOURNAL OF SCIENTIFIC RESEARCH

\title{
INTRAPANCREATIC ACCESSORY SPLEEN MIMICKING A NONSECRETING PANCREATIC NEURO ENDOCRINE TUMOR : A CASE REPORT
}

Hepatobiliary Surgery
$\begin{aligned} & \text { Dr. Mahesh S. } \\ & \text { Shetty }\end{aligned}$
$\begin{aligned} & \text { Dr. Sunil Kumar } \quad \text { Associate Professor, Department of Surgical Gastroenterology, JSS Hospital, Mysuru. } \\ & \text { B.B. }\end{aligned}$

Dr. Ankit Raj*

Resident , Department of General Surgery, JSS Hospital , Mysuru. *Corresponding Author

\section{ABSTRACT}

The accessory spleen is a congenital anomaly caused by a failure in embryologic development of spleen tissue with occurring in $10 \%$ of general population. In $16 \%$ of these cases, this tissue is found in tail of the pancreas. Here we present a case of 55 year old female who presented to our OPD with complaints of recurrent pain abdomen. CT showed a mass in the tail of pancreas with thrombosis of superior mesenteric artery .Patient underwent spleen sparing distal pancreatectomy with celiac axis to hepatic artery bypass and mass was sent for analysis. The pathological examination showed an intrapancreatic splenic tissue. As a rare ectopic location of spleen tissue and it should be considered in the differential diagnosis of pancreatic solid tumors. IPAS should be considered as a differential diagnosis in patients with suspected incidental pancreatic neuroendocrine tumour. Preoperative diagnosis is important as unnecessary surgery can be avoided

\section{KEYWORDS}

Spleen ; Pancreas ; Neuroendocrine tumors ; Diagnosis, differential

\section{INTRODUCTION}

Ectopic splenic tissue otherwise known as Accessory spleen (AS) is a congenital abnormality present in approximately $12 \%$ of patients in autopsy series. It arises due to fusion failure of multiple splenic anlages located in the dorsal mesogastrium during the fifth week of the embryonic life. The location of AS varies, but includes splenic hilum, the tail of the pancreas, the greater omentum and the splenic ligament. Accessory spleens are usually of little clinical consequence and found incidentally during surgery for other indications. Intrapancreatic Accesory spleen (IPAS) are uncommon with $11 \%-17 \%$ of all ASs being located in the pancreatic tail in autopsy studies. AS can be seen in approximately $10-20 \%$ of individuals which makes the prevalence of IPAS between $1.1 \%$ and $3.4 \%$. IPASs are rarely encountered or diagnosed by imaging modalities as most of them are relatively small and do not cause clinical symptoms. There is not much published data available on IPAS regarding epidemiologic features, clinical manifestations, tumor biomarker abnormalities or imaging characteristic . Since it is a benign entity and is mostly asymptomatic, IPAS generally does not require therapy unless associated with any other complications such as idiopathic thrombocytopenic purpura (ITP) or is symptomatic Hence, correct diagnosis of the lesion is necessary to differentiate from other causes and to avoid unnecessary operative intervention resulting in increased morbidity of the patient.

\section{- Case :}

A $55 \mathrm{yr}$ old female presented to the opd with c/o pain abdomen on and off since past 4 months which had aggravated since past 1 week. Pain was insidious in onset, dull aching in nature not associated with any aggravating factors and relieved on medication .Patient did not give any $\mathrm{h} / \mathrm{o}$ trauma, fever or any other associated complaints. She underwent appendicectomy $30 \mathrm{yrs}$ back and is a known hypertensive on medication.

Clinical examination of the patient was unremarkable .USG abdomen and pelvis showed a hyperechoic mass in the tail of pancreas with $\mathrm{f} / \mathrm{s} / \mathrm{o}$ Superior Mesenteric Artery (SMA) thrombosis . Patient was followed up with CECT abdomen and pelvis which showed a well defined soft tissue lesion $2 \times 1.5 \times 1.4 \mathrm{~cm}$ in the tail of pancreas? Neuroendocrine tumour of pancreas with complete SMA thrombosis alongwith compensatory dilatation of Inferior mesentric artery with no features suggestive of Mesentric ischaemia.

Tumour markers were found to be within normal range. In view of persistent pain patient and suspected malignancy the patient was taken up for spleen sparing distal pancreatectomy with celiac trunk to common hepatic artery bypass. Intraoperatively pancreas was noted to be having increased fatty strands. Post resection specimen was sent for histopathology examination which confirmed it to be intrapancreatic accessory spleen .

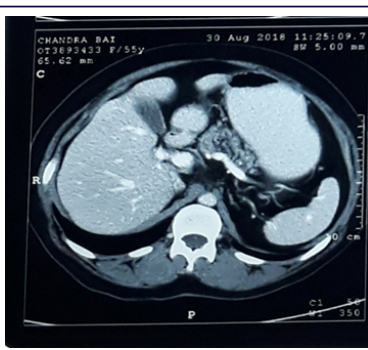

Fig1 CECT Abdomen and pelvis showing a soft tissue lesion in the tail of pancreas

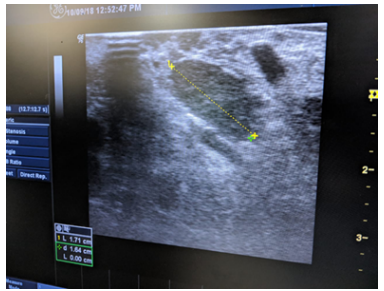

Fig 2 Intra operative ultrasound confirming the mass lesion in the tail of Pancreas

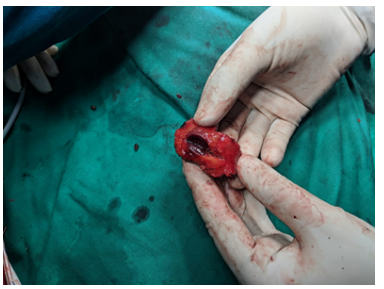

Fig 3 Specimen

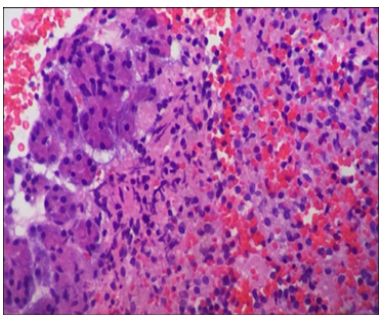

Fig 4 Shows ectopic splenic tissue with white pulp (darker purple) on the upper left and red pulp in the middle with residual normal pancreas tissue 


\section{DISCUSSION}

An accessory spleen mainly presents as an isolated asymptomatic lesion, but it may have clinical significance in some conditions . Differential diagnosis for a case of mass in the tail of the pancreas may include a solid pseudopapillary tumor, mucinous cystic neoplasm, pancreatic endocrine neoplasm, pancreatic adenocarcinoma, metastasis, and Intra pancreatic accessory spleen (IPAS) ${ }^{[1]}$. Since an accessory spleen does not usually require treatment, accurate preoperative diagnosis is important. IPAS sometimes may be difficult to differentiate from hypervascular pancreatic tumors such as pancreatic endocrine neoplasms and ductal carcinomas due to similar enhancement patterns ${ }^{[2]}$. Hence, most of the reported cases of IPAS have been diagnosed only on histopatological examination post surgery ${ }^{[3]}$.

Now a days main diagnostic modality to confirm IPAS preoperatively is radiological .On ultrasonography, IPASs are well defined and round, ovoid or lobulated. The echogenicity of most IPASs is low as compared to pancreatic parenchyma but identical to that of the main spleen. In some cases blood supply to IPASs from splenic artery or vein can be seen on color Doppler. Multiple imaging studies have been suggested to differentiate IPAS radiological findings such As ${ }^{99 \mathrm{~m}} \mathrm{Tc}$ Sulfur Colloid With Coronal Single-Photon Emission CT, Indium 111Labeled Autologous Platelets, Technetium-99mc Radiolabeled HeatDamaged Red Blood Cells, Reticuloendothelial System-Specific Contrast Medium called Ferucarbotran, And Contrast-Enhanced Ultrasound.

As per a study done by Mortelé et al ${ }^{[4]}$ abdominal CT scans were performed on 1000 consecutive patients. Out of these 1000 cases ; 156 $(15.6 \%)$ had at least one accessory spleen, and 21 (13\%) had more than one accessory spleen, with a maximum of three accessory spleens per patient, resulting in a total of 180 accessory spleens. Their anteroposterior diameter ranged from 4 to $29 \mathrm{~mm}$, with an average of $11.9 \mathrm{~mm}$. The transverse diameter was between $4-25 \mathrm{~mm}$, with an average of $11.6 \mathrm{~mm}$. Most were located at the hilus of spleen. IPASs were seen in 2 patients. Most accessory spleens have a characteristic appearance on CT, and are well-defined, round masses being smaller than $2 \mathrm{~cm}$ in diameter. with homogeneous enhancement. In this study, however $32 \%$ of the accessory spleens were hypodense compared with the main spleen. Since all the accessory spleens were less than $1 \mathrm{~cm}$ in diameter, their attenuation might have been caused by partial volume effects. It is likely that, when thinner collimation (e.g. $\leq 5 \mathrm{~mm}$ ) is used, accessory spleens may appear similar to the spleen.

The most specific diagnostic modality for ectopic splenic tissue is nuclear scintigraphy using technetium-99m-labeled sulfur colloid or 99mTc-labeled heat-damaged RBCs but due to inferior anatomic resolution with respect to $\mathrm{CT}$ and MRI, false negative results may be more ${ }^{[1]}$ Endoscopic ultrasound (EUS)-guided fine-needle aspiration (FNA) biopsy is also a highly sensitive for the evaluation of pancreatic lesions. Schreiner et. $\mathrm{al}^{[5]}$ reported 3 cases of IPASs which were diagnosed using EUS-guided FNA, which revealed predominantly small lymphocytes with a subset of histiocytes, conspicuous eosinophils, and plasma cells.

As per a study done by Lauffer et $\mathrm{al}^{[6]}$ any nonenhancing hypervascular mass is an indication for noninvasive study. In these cases, a negative biopsy result may not rule out malignancy. Any solid, hypervascular lesion in the tail of the pancreas should be treated as a neoplasm until proven otherwise. It has been reported that up to $29 \%$ of pancreatic resections for presupposed tumors are found to be benign ${ }^{[7]}$. Since preoperatively diagnosis of IPAS requires a very high index of suspicion, and distal pancreatectomy is a safe and relatively simple operation most of the reported cases of IPAS are diagnosed only after surgery $^{[8]}$.

\section{CONCLUSION}

It is difficult to make a definite diagnosis of IPAS by one single modality as the features of IPAS differ between individuals due to the diversity of red/white pulp ratio. As most of the IPASs are asymptomatic and do not pose a threat, they don't require medical treatment. IPAS, especially an enhancing pancreatic lesion, is generally misdiagnosed as a pancreatic neuroendocrine tumour, therefore leading to unnecessary surgical intervention. Therefore it is imperative that IPAS should be considered as a differential diagnosis for a pancreatic mass and, when suspected, consider further investigations to determine the true nature of the underlying lesions.

\section{REFERENCES}

1. Sica G.T., and Reed M.F.: Case27: intrapancreatic accessory spleen. Radiology 2000; 217: pp. 134-137

2. Ota T., Tei M., Yoshioka A., et al: Intrapancreatic accessory spleen diagnosed by technetium-99m heat-damaged red blood cell SPECT. J Nucl Med 1997; 38: pp. 494 495

3. Ota T., and Ono S.: Case report intrapancreatic accessory spleen: diagnosis using contrast enhanced ultrasound. Br J Radiol 2004; 77: pp. 148-149

4. Mortelé KJ, Mortelé B, Silverman SG. CT features of the accessory spleen. AJR Am J Roentgenol. 2004;183:1653-1657

5. Schreiner AM, Mansoor A, Faigel DO, Morgan TK. Intrapancreatic accessory spleen: mimic of pancreatic endocrine tumor diagnosed by endoscopic ultrasound-guided fineneedle aspiration biopsy. Diagn Cytopathol. 2008;36:262-265

6. Lauffer J.M., Baur H.U., Maurer C.A., et al: Intrapancreatic accessory spleen, a rare cause of a pancreatic mass. Int J Pancreatol 1999; 25: pp. 65-68

7. Spinelli K.S., Fromwiller T.E., Daniel R.A., et al: Cystic pancreatic neoplasms observe or operate. Ann Surg 2004; 239: pp. 651-659

8. Hayward I., Mindelzun R., and Brook R.: Intrapancreatic accessory spleen mimicking pancreatic mass on CT. J Comput Assist Tomogr 1992; 16: pp. 984-985 